instruction from Dutch to English so that Holland could boost its attraction for international students and integrate more fully into the global scholarly community. The Dutch Parliament debated the issue and decided not to shift the language-arguing that the Netherlands would lose its distinctive culture if the Dutch language was no longer used for intellectual and academic life. This argument is relevant elsewhere. If the knowledge that is most valued is aimed at the international academic world and is communicated in English, there will be negative implications for national scientific and intellectual systems.

In many countries, academic rewards of all kinds accrue to those using English and participating in global scientific networks. These scholars are typically invited to international conferences, awarded research funds by both international and national funders, and are generally seen as leaders of their scientific communities. Universities and governments often use the SCI and related systems to judge the impact and value of their academics and universities. SCI becomes a kind of proxy for quality and productivity. Similarly, the international ranking systems use such measures. However, again, this offers privileges those who produce their work in English and intend to reach an international audience.

These factors will tend to orient researchers and scholars to themes that they feel will appeal to an international audience, often at the expense of essential but more parochial themes that might be of interest only to local or national audiences. Further, the methodologies chosen for research will follow those popular internationally, whether these methods are relevant to the specific topic being researched.

The current debate concerning the General Agreement on Trade in Services (GATS) as part of the World Trade Organization (WTO) has direct implications for this discussion. GATS will force academic systems worldwide to be more open to foreign influences. Should GATS be widely implemented, this will inevitably mean the English-language institutions and programs will further entrench themselves worldwide.

These factors lead to homogenizing knowledge worldwide. Not only is English the dominant language, but its relationship with the controlling trends in international science and scholarship is a powerful combination of forces contributing to decreasing diversity of themes and methodologies.

\section{What Can Be Done?}

If globalization determines the direction of the world economy, science, and other factors, then the growth of English as the global language of science and scholarship is inevitable for the foreseeable future. Science indeed is increasingly international, and the global mobility of students and professors is a longterm reality. There is an international knowledge network that involves not only science and scholarship but increasingly people. This network operates mainly in English and is dominated by the main English-speaking academic systems.
The argument here is that the international network is both inevitable and largely positive but that national and local scientific communities and higher education systems must be protected. These communities deserve both respect and support because they bring a valuable perspective and diversity to science and scholarship. Internationalization may be positive but with homogenization we lose a concern for local and regional issues as well as ideas that may not be in the international mainstream. An entirely open market will weaken these communities, just as the major world languages today are snuffing out small and weak languages. Science and scholarship in national languages deserve support. The evaluation of academic merit should not depend solely on the rankings of the SCI or other exogenous agencies-and thus left to the judgment of foreigners. While local evaluation may not be easy, it is necessary. An appropriate mix between local and international publication will help nurture an active research community.

The essential necessity is an understanding of the importance of national scientific and intellectual communities. Creating a balance between the local and the global may not be easy but intellectual independence depends on it.

\section{The Global Higher Education Race}

\section{John Aubrey Douglass}

John Aubrey Douglass is senior research fellow at the Center for Studies in Higher Education at the University of California, Berkeley. Address: Center for Studies in Higher Education, South Hall Annex, University of California, Berkeley, CA 94720-4650, USA. E-mail: douglass@berkeley.edu.

The United States pioneered the idea of mass higher educa1 tion, reaping tremendous economic and social advantages. Now much of the world has embraced this model on its own political and cultural terms. The higher education race is driven by the idea that education will increasingly play a decisive role in national economic competitiveness and socioeconomic mobility. As a result, higher education has become a major global growth sector. Despite significant differences among nations and regions in the structure and culture of their academic enterprises, certain similarities in policy approaches and trajectories are creating, in turn, dramatic enrollment and program growth.

Yet in the midst of this global trend, America has entered a period of stagnant higher education access and graduation rates. This downturn is perhaps not fully understood through- 
out the world or in the United States.

\section{Access in the United States}

Overall, the United States still retains a lead in the number of people with higher education experience and degrees, according to data from the Organization for Economic Cooperation and Development (OECD). But about the younger age cohort, a different story emerges. On average, the postsecondary participation rate for persons aged I8 to 24 in the United States was approximately 34 percent in 2005 , down from around 38 percent in 2000.

In the United States, more students today are part time, and more are attending two-year colleges. The wealthiest students are in the four-year institutions. Students from lower- and even middle-income families are now more likely to attend a twoyear college, less likely to earn a bachelor's degree, and now take much longer to attain a degree than in the past. This appears as an alarming trend, although with complicated causes that do not lend themselves to easy policy solutions.

In contrast, within a comparative group of fellow OECD countries, many nations are approaching and a few have exceeded a 50 percent participation level of their younger age group in postsecondary education. Another difference lies in the fact that some 45 percent of all students in the United States attend two-year community colleges, whereas most students in the European Union (EU) are enrolled in programs that lead to a bachelor's degree.

One reason for the US lag is that in 2004 it ranked only Igth in secondary school graduate rates, possibly an optimistic estimate. When compared with other industrialized nations, the United States ranked only I4th in the percentage of the population that enters postsecondary education and then completes a bachelor's degree or higher. As a result, the United States is one of the few OECD nations in which the older generation has achieved higher tertiary education rates than the younger sector.

In some states-such as California, the first state to invest in a comprehensive approach to mass higher educationaccess to postsecondary education for the traditional age cohort has declined significantly over the past two decades. In I970, some 55 percent of all public high school graduates in California moved directly to tertiary education, among the highest rate in the nation; in the year 2000, the rate was a mere 48 percent, with the vast majority going into community colleges, most as part-time students and most destined never to attain a two-year let alone a bachelor's degree. This has occurred in an economic environment in which demand for a labor pool with postsecondary training and education is expanding.

One 2006 study estimates that by the year 2022, one in three new California jobs generated will require an associate degree, bachelor's degree, or higher. Jobs requiring higher education are already growing faster than overall employment in the state.

\section{ObSERVATIONS ON COMPETITORS}

Within the EU, the push to increase participation rates in higher education transcends national borders. So important is the expansion of universities for EU nations that many countries are now integrating degree standards (like the American model) under the I999 Bologna declaration. As of May 2005, 45 signatory countries joined the Bologna process.

In Europe, the rhetoric regarding markets and deregulation does pervade much of the talk about how to advance participation rates. However, governments by and large are launching reforms and creating bureaucratic regulatory regimes focused on access, productivity, and quality.

Another difference lies in the fact that some 45 percent of all students in the United States attend twoyear community colleges, whereas most students in the European Union (EU) are enrolled in programs that lead to a bachelor's degree.

Moreover, government plays a heavier hand in Europe than in the United States, in part because of historical and cultural differences. The development of public higher education in America has largely followed an organic process of building institutions and creating self-regulated systems over a long time. On the other hand, in Europe and most of the world, until the ig6os (and arguably, later in many countries), higher education constituted an elite function transformed by governments.

\section{Stagnation in the United States}

What factors contribute to this erosion of America's once dominant position in higher education? The array of interrelated causes can be boiled down to four main factors.

As noted, one reason is the uneven quality of high schools in the United States and, in some states, real declines in high school graduation rates. Another important cause is the drop in the political interest and government investment in public higher education (where some 80 percent of all American students are enrolled). The federal and state partnership that devoted significant resources to building mass higher education in the United States throughout the last century has dissipated. This phenomenon helps generate a third cause: increased fees without adequate increases in financial aid.

With the exception of political battles in America over admissions to a few selective public universities and concerns over cost containment, American higher education remains a second-tier political issue. The crisis of the public sector-the underinvestment in public colleges and universities, which are the primary providers of postsecondary education-is not a mainstream political concern. For this and a variety of other 
reasons, the United States has become relatively complacent in maintaining its higher education advantage.

Author's note: This article is adopted from the author's new book, The Conditions for Admissions: Access, Equity, and the Social Contract of Public Universities.

\section{Where Are Global Leaders Educated?}

\section{Moosung Lee}

Moosung Lee is a PhD candidate in the Department of Educational Policy and Administration at the University of Minnesota. Address: 269 Appleby Hall, 128 Pleasant Street SE, Minneapolis, MN 55455, USA. E-mail: leex2125@umn.edu.

$\mathrm{T}$ The increasing global influence of international organizations creates some curiosity about the educational backgrounds of top officials in leading international organizations. This article explores which universities are regarded or preferred as world-class universities by recruiters in the leading international organizations. Data were obtained from the Year Book of International Organizations (2005-2006) and Who's Who in International Organizations (2006), which include I5,354 leading organizations ranging from United Nations agencies to virtually every type of international organization. As such, the educational backgrounds of 2,563 high-ranking officials were identified-encompassing secretaries-general, directors-general, deputy and assistant directors-general, and department heads. Included in this sample were top officials holding one or more of the higher education degrees (i.e., bachelor's, master's, and doctoral).

\section{Education of Global Leaders}

The majority of these global leaders were trained at Western universities. Of the 2,563 high-ranking officials, 88.5 percent of them earned at least one higher education degree at Western universities. In particular, almost half of these alma maters are located in two English-speaking countries: the United States, 27.4 percent, and the United Kingdom, I8.8 percent. These national figures to some extent reflect the percentage of global elite universities located in these two nations, as suggested by the rankings of the Times Higher Education Supplement (THES) and Shanghai Jiao Tong University (SJTU). For example, the 2005 THES ranking reveals that 26.5 percent of the top 200 universities were located in the United States, which is consistent with the percentage of the top officials educated in the United States (27.4\% of the top 2,563 officials). Also, I6 per- cent of the top 200 universities were located in the United Kingdom according to the 2005 SJTU data-similar to the percentage of the top officials educated in the United Kingdom (I8.8\%). The prestigious universities in those two countries served as the major source for top officials. A striking II.7 percent of the 2,563 officials were cultivated by only four universities: Harvard (4\%), Oxford (3.4\%), Cambridge (2.5\%), and Yale (т.8\%).

Another distinctive feature was that 4I percent of top officials turned out to be educated in western European countries other than in the United Kingdom. The institutions where 29.5 percent of top officials were educated were located in four European countries: France (II.5\%), Belgium (8.8\%), Germany (4.9\%), and the Netherlands (4.3\%). These top officials were educated in I9 cities in countries where several well-known universities are clustered-for example, Paris (e.g., Paris I to Paris XIII, and École Normale Supérieure) and Brussels (e.g., Université Libre de Bruxelles and Université Catholique de Louvain).

The leading position of Western universities in supplying officials for these international bodies means that many nonWestern universities were thus marginalized in terms of shaping the membership structure of these organizations. Only II.5 percent of the top officials were educated at universities in Asia Pacific (6.3\%), Latin America (2.I\%), eastern Europe (1.8\%), and Africa (I.3\%). Even academically well-known universities in the Asia Pacific region lagged far behind their Western counterparts in generating global leaders. Only 6.3 percent of the top officials were educated at universities in the Asia Pacific region, where 5I universities out of the top 200 (25.5\%) were located, according to THES. More specifically, while I7 Australian universities were ranked in top 200 by the THES, only 0.7 percent of the top officials were educated at Australian universities.

The leading position of Western universities in supplying officials for these international bodies means that many non-Western universities were thus marginalized

\section{Advantage of Geographic Location}

An investigation confirms that this hiring disparity cannot be explained by school rankings. Located in four western European countries, the universities that are producing many global leaders were generally ranked lower than certain wellknown universities in the Asia Pacific region and even North America (e.g., Tokyo, Beijing, Melbourne, Australia National University, Michigan, and Toronto). For example, 8.8 percent of top officials were educated in Belgian universities, but only four Belgian universities were ranked among the top 200 